\title{
Classe Média Negra Universitária: por um projeto de sociedade afirmativa
}

Recebido: 16-04-2018

Aprovado: 01-11-2018

\author{
Ricardo Dias de Castro ${ }^{1}$ \\ Claudia Mayorga ${ }^{2}$
}

\section{A Democratização do Ensino Superior Público e o Novo Corpo Discente da Universidade}

O debate das ações afirmativas, no Brasil, ainda que não fosse um consenso político; certamente, tem alcançado outro patamar nos debates públicos, acadêmicos e militantes pelo país. Há anos atrás, os movimentos negros ${ }^{3}$ e os intelectuais do pensamento da raça e do racismo tinham que se desdobrarem em complexas e profundas lutas políticas, teorias, pesquisas e investigações empírico-ideológicas que comprovassem a existência do racismo e a funcionalidade das políticas afirmativas em um país como o nosso. Essa continua sendo uma realidade de vários pesquisadores, pensadores e militantes antirracistas que ainda precisam se esforçar em lançar luz às dinâmicas invisíveis - e na, mesma medida, violentas - do racismo à brasileira. No entanto, é fato que o debate em torno das ações afirmativas avançou na direção de sua força pública e política, nos últimos anos; culminando, por exemplo, na sua federalização pelo Supremo Tribunal Federal em 2012.

Ainda com essa e outras conquistas públicas/políticas afirmativas; o Brasil permanece atualizando e reproduzindo velhas e sofisticadas formas de atuação de discriminações que se baseiam, sobretudo, numa crença discursiva - e, portanto, social- de que os negros são sujeitos, racialmente, inferiores. Algo que ainda acionamos em nossos pensamentos e práticas a partir de um discurso colonial de poder que afirma, por exemplo, que os grupos,

\footnotetext{
${ }^{1}$ Professor na Faculdade Ciências da Vida (FCV) e doutorando pelo Programa de Pós-Graduação em Psicologia da Universidade Federal de Minas Gerais (2018).E-mail: ricardodiascastro@gmail.com

${ }^{2}$ Professora do Departamento de Psicologia da Universidade Federal de Minas Gerais e do Programa de Pósgraduação em Psicologia. Coordenadora do Núcleo de Ensino, Pesquisa e Extensão Conexões de Saberes na UFMG. E-mail: mayorga.claudia@gmail.com

3 Aqui, fazemos uso desse termo no plural para indicar a diversidade de experiências, demandas, lutas, estratégias e bandeiras em torno da categoria da negritude política brasileira. Fazemos isso como modo de não assumirmos os movimentos antirracistas como sendo unificados, homogêneos ou sem conflitos.
} 
racialmente, negros são incapazes de chegar ao progresso do conhecimento e à civilização (QUIJANO, 2005). Reconhecemos, nesse sentido, que, historicamente, os sujeitos negros são associados às mais diversas carências (econômicas, intelectuais, culturais, materiais, estéticas e simbólicas) que são reiteradas como verdades totais ou destinos naturais para todo e qualquer negro brasileiro. O que tem impossibilitado, aos negros, o seu acesso a uma série de direitos e serviços dos dispositivos “democráticos” do Estado (SKIDMORE, 2013).

A universidade, nessa direção, tem sido um dos espaços sob os quais a discussão das cotas, das ações afirmativas e da democratização do ensino público tem recaído; na medida em que a Educação - como qualquer outra instituição democrática brasileira - foi construída na subalternização e no alijamento dos saberes, das cosmologias e das propostas epistemológicas dos africanos e dos afro-brasileiros (FONSECA; BARROS, 2016; GROSFOGUEL, 2016). Em um movimento contrário, no entanto, a história dos movimentos negros e da intelectualidade antirracista nos mostra como sujeitos e coletivos construíram condições de se posicionar críticos e contrários a toda uma matriz de ensino, educação, sociedade e universidade que evitou abarcar, apoiar e reconhecer aspectos e as potencialidades de um saber e de uma experiência que fosse afro-brasileira, multirracial e pluriétnica (DÁVILA, 2006; GOMES, 2017; PIRES, 2014).

Ora, uma vez que o espaço da universidade começa a se ressignificar a partir de pressões do movimento negro e das políticas das ações afirmativas, pela presença de sujeitos negros e pela fortificação do pensamento intelectual sobre raça e racismo; abre-se uma brecha no ensino superior público numa dimensão maior do que podíamos prever. Em um país em que a negritude é associada às mais diversas carências; tomar a universidade como um lugar de poder que, sócio-ideologicamente, foi construído por brancos e para brancos, é primordial para que nos interroguemos sobre as trajetórias, as vivências, os pensamentos e as práticas de negros que compõem o corpo discente da universidade (MAYORGA, 2010; TEIXEIRA, 2003).

Ainda nessa direção, a partir de mudanças que foram efeito da distribuição de renda, da diminuição de pobreza e do crescimento do emprego - principalmente o púbico - e da formalidade no mercado de trabalho; a última década trouxe melhorias significativas para uma grande parte da população brasileira, o que tem sido capaz de elevar os rendimentos e o poder de consumo de muitas famílias (ANDREWS, 2007; OSORIO, 2004; SALATA, 2015). Nesse sentido, há negros, que nos últimos anos, têm ocupado as classes econômicas médias ou, até mesmo, de estratificações superiores e, nesse sentido, têm circulado em espaços de poder e privilégio onde há uma maior circulação de sujeitos reconhecidos brancos e a 
restrição de negros era limitada, ou até mesmo, negada. Como desdobramento, podemos identificar um novo imaginário social acerca dos negros em ascensão, o que torna a pergunta sobre esses sujeitos um problema para o pensamento social brasileiro (CASTRO, 2017; FIGUEIREDO, 2002, 2004, 2012; FIGUEIREDO; FURTADO, 2014; LERNER, 2015; NOGUEIRA, 2007; SANTANA, 2014; SOARES, 2004).

Um problema, sobretudo, porque segundo Figueiredo (2002, 2004, 2012, 2014) o estudo da classe média negra, ainda que importante para pensarmos as relações raciais no Brasil, esteve à margem dos grandes temas que dominaram esse campo de estudos no país e, segundo a pesquisadora, os poucos trabalhos sobre negros em ascensão social acontece pela polêmica que envolve esses sujeitos. Esse segmento parece ser considerado, pelos pesquisadores, como um objeto de pesquisa "pouco simpático", uma vez que são lidos como traidores - que no processo de ascensão - esqueceram-se dos negros ou como "metidos a branco" que incorporaram valores e estilos da classe média branca, na tentativa de embranquecerem socialmente (D’ADESKY, 2003)

Evitaremos, aqui, no entanto, as armadilhas dicotômicas na produção de um conhecimento acerca da experiência e dos dilemas de sujeitos que parecem participar de dois mundos, regidos por regras e códigos de valores, historicamente, distintos (FIGUEIREDO E FURTADO, 2014). Nesse artigo, na direção contrária, faremos um caminho analítico dialógico que possa ler a universidade e o seu processo de democratização a partir das narrativas de universitários negros da classe média da UFMG; ainda que essa posição - ser negro e universitário - tenha sido impedida, historicamente, pelo projeto moderno racista de universidade.

\section{Barreiras (in)visíveis: a branquitude e o lugar da universidade pública}

Tomamos, aqui, a universidade como um espaço analítico, ou seja, apostamos em uma compreensão na qual a universidade deixe de ser, apenas, um local físico e possa, por outro lado, denunciar-nos lugares sociais e simbólicos da sua organização social e da sociedade. Partimos de uma compreensão da universidade, nessa direção, como uma instituição que revela problemas e dilemas que marcam a sociedade brasileira, produzindo e reproduzindo lógicas de poder. Mas que, em contrapartida, também constrói espaços para o seu enfrentamento e resistência. Nesse sentido, olhar para a universidade desvelando a lógica elitista (branca), meritocrática e segregacionista na qual ela foi construída, dar-nos-á elementos para pensar a sua institucionalização na subalternização dos conhecimentos, das 
vivências e dos povos negros. A história da universidade, no Brasil, é muito complexa e nada consensual. E, aqui, gostaríamos de reforçar a parte do seu histórico que denuncia os ideais eurocêntricos, brancos e elitistas nos quais o projeto universitário brasileiro se sustentou (MAYORGA, 2010).

Nessa direção, a história da universidade brasileira nos aponta para como a sua construção teve a ver com uma intenção de sociedade que possui efeitos até hoje. Feres Júnior (2006) ao discorrer sobre como se deu o processo de importação de um projeto moderno de sociedade para o Brasil, explicita que junto a essa noção de moderno; teorias e pensamentos racistas foram, também, importados no período em que o Brasil começava a pensar em um projeto nacional de unificação.

O que chega ao Brasil não é só uma estrutura normativa da modernidade, mas um complexo de
ideologias, instituições e teorias científicas, muitas delas contraditórias, que vieram se somar as
já existentes no Brasil imperial. É desse encontro, e de desenvolvimentos históricos
posteriores, que se desenvolve a semântica do preconceito racial no Brasil de hoje. E é o
preconceito racial o material bruto privilegiado para estudarmos a negação do reconhecimento
dos não-brancos em nossa sociedade (FERES JUNIOR, 2006, p.171)

Isso significa que todos os elementos que atravessaram a construção de um país antes colonizado e agrário - para um país industrial e arrojado; foram embebidos em um projeto ocidental branco de progresso. Os efeitos desse projeto brancocentrado de sociedade moderna tem sido um dos principais pilares de construção de lugares de poder na sociedade brasileira: vide os princípios de individualismo, meritocracia, supervalorização do privado em detrimento do público e uma universalização que elimina e desconsidera saberes e experiências não hegemônicos. Com a universidade ocidentalizada nas sociedades coloniais não foi muito diferente. A instituição do ensino superior, pode-se dizer, foi construída em cima da subalternização dos povos negros e indígenas que foram alijados da construção e da participação desses espaços de prestígio sócio-cultural-econômico das elites (DÁVILA, 2006; GROSFOGUEL, 2016).

É possível perceber que se as elites brasileiras, em um primeiro momento, resistiram a construir o ensino superior público na colônia - ameaçada pela possibilidade de que os colonos e os escravos pudessem pensar autonomamente e ter acesso àquilo que poderia descolonizá-los em alguma medida - ; será pela mesma referência brancocentrada que a universidade vai se instituir no país. Isto é, a partir de uma regulação, cujos critérios pudessem propiciar a manutenção desses mesmos privilégios brancos da elite nos espaços de poder e saber. É, nessa direção, que aproximamos a história da universidade com a branquitude - a sistemática manutenção econômica e política de brancos na elite intelectual 
(CASTRO, 2017; CUNHA, 2000; SCHUCMAN, 2012). Dentro desse cenário, é primordial que possamos compreender a especificidade e os elementos que dão sustentação a preconceito e a discriminação racial para sujeitos que puderam vivenciar uma ascensão social, intelectual e, até mesmo, econômica em uma instituição com origens tão coloniais como a universidade pública brasileira. Ao mesmo tempo, precisamos nos atentar para as construções individuais, coletivas e políticas que possibilitam a interpelação do ensino superior público e de suas égides racistas e classistas (GOMES, 2017; MAYORGA, 2010; TEIXEIRA, 2003).

Nesse sentido, a branquitude opera, portanto, como uma posição em que sujeitos que a ocupam foram e são, sistematicamente, privilegiados no que tange ao acesso a recursos materiais e simbólicos gerados pelo colonialismo e pelo imperialismo, e que, atualmente, são reatualizados e preservados. É “uma rede na qual os sujeitos brancos estão consciente ou inconscientemente exercendo-o em seu cotidiano por meio de pequenas técnicas, procedimentos, fenômenos e mecanismos que constituem efeitos específicos e locais de desigualdades raciais" (SHUCMAN, 2012, p.23). Essa lógica e essa posição são permanentes esforços de exclusão moral, afetiva, econômica e política de não-brancos, no universo social e, aqui, mais propriamente, apontamos a produção de uma barreira intelectual imputada, historicamente, aos negros como um efeito dessa suposta e naturalizada supremacia branca (FONSECA; BARROS, 2016).

\section{Classe Média Negra e o Desejo pelo Diploma Universitário}

Os estudos sobre a classe média negra tornaram-se fortes, principalmente, dentro do contexto da mobilidade socioeconômica de negros norte-americanos. Intelectuais estadunidenses da época, preocupados em investigar como se deu a entrada dos descendentes de escravizados no sistema do capital e do mercado moderno, construíram estudos em torno da chamada Black Bourgeoisie, do Black Business e do Black Enterpreneur (FIGUEIREDO, 2002). Esses campos de estudos refletiam os desejos e as expectativas dos negros norteamericanos da primeira metade do século passado em torno da relação complexa entre a mobilidade e/ou ascensão social, o desenvolvimento econômico, a emancipação política e a solidariedade entre os negros de diferentes classes sociais.

Acontece que, ainda que esses dados norte-americanos tenham servido, inicialmente, para pensarmos uma literatura científica da classe média no Brasil; a complexidade do campo da desigualdade racial e econômica nacional nos exigiu algumas especificidades de análise de modo que abríssemos mão de uma perspectiva apenas comparativa com os estudos 
estadunidenses.

Por sua vez, o estudo da classe média negra, ainda que muito importante para a compreensão das dinâmicas sociorraciais brasileiras, esteve à margem dos grandes temas que dominaram os estudos das relações raciais no Brasil. Constatando-se, portanto, uma falta de informações e de bibliografia que poderiam melhor orientar as pesquisas sobre negros da classe média no Brasil. E diante da identificação de negros que realizaram mobilidades socioeconômicas consideráveis, tornou-se inevitável que pesquisas, ainda que incipientes, tentassem enfrentar esse problema em torno da intersecção entre ser negro e ter acesso ao dinheiro (FIGUEIREDO, 2012)

\begin{abstract}
As pesquisas sobre relações raciais, cultura e identidade negra no Brasil têm privilegiado exclusivamente os negros que estão situados na base da hierarquia social, em detrimento aos estudos sobre os negros que ocupam melhores posições. Até o momento, muito pouco se tem pesquisado sobre as estratégias que os negros utilizam para ascenderem socialmente. É consensual a percepção de que alguns espaços do mercado de trabalho têm se constituído em áreas mais fáceis para a ascensão social dos negros, a exemplo do esporte e da música, embora essas atividades reservem poucos lugares para os aspirantes à mobilidade (FIGUEIREDO, 2012, pp. 31-32).
\end{abstract}

Porém, foi possível perceber, em algumas pesquisas brasileiras sobre a ascensão social, status e prestígio dos afro-brasileiros; que a educação foi se tornando o principal dispositivo no processo de mobilidade para a população negra. De modo que a expansão e democratização da educação formal permitiu uma redistribuição mais equitativa das possibilidades de mobilidade ascendente dos negros através do aumento do nível educacional (CASTRO, 2017; FIGUEIREDO, 2012).

Nessa direção, não é sem sentido que reconheçamos que a pobreza brasileira, certamente, tem cor, denotando uma discrepância simbólica, econômica, intelectual e cultural entre negros e brancos no Brasil em função do histórico do sistema econômico-político escravocrata (PINHEIRO et al, 2009; CARNEIRO, 2011). No entanto, processos históricos de transformações materiais e simbólicas possibilitaram que alguns negros pudessem começar a circular em espaços da elite. Desse modo, analisar as elites constituídas por grupos minoritários, é destacar a experiência de sujeitos que possuem a vivência de um lugar hegemônico na sociedade e de outro lugar desprestigiado, racializado e inferiorizado (FIGUEIREDO; FURTADO, 2014)

Uma vez que, em geral, sujeitos negros - com trajetórias marcadas por posições de privilégio, poder e prestígio parecem ter estado fora da literatura clássica sobre o tema torna-se importante inserir essas experiências em nosso pensamento social para que não naturalizemos lugares negros e lugares brancos a níveis ontológicos. Nessa direção, 
Figueiredo (2002, 2012) afirma compartilharmos uma ideia na qual existe uma incompatibilidade entre ser negro e poder desfrutar dos bens associados à modernidade, uma vez que a representação sobre o lugar do negro, na sociedade brasileira, parece homogeneizar as associações entre cor e classe (ricos e brancos $\mathrm{X}$ pretos e pobres).

O que é possível perceber é que, em relação a outros grupos étnicos no Brasil, como armênios, sírios, libaneses, italianos, japoneses, chineses e alemães - e, também, para os negros norte-americanos - a identidade étnica foi um importante instrumento no projeto de ascensão socioeconômica. A ascensão desses grupos imigrantes, no Brasil, foi facilitada pela ajuda mútua e pela identidade étnica associada ao exercício de determinadas atividades profissionais que resultaram em guetificacões de mercado. Por sua vez, a classe média negra norte-americana, cujo advento é marcado pela recusa dos comerciantes brancos em atender aos consumidores negros, no contexto do apartheid, desponta um grupo de profissionais afroamericanos liberais para servirem às demandas das populações isoladas afro-americanas (FIGUEIREDO, 2002).

Em um movimento contrário a esse pertencimento afirmativo étnico e mercadológico, a ascensão social dos negros brasileiros tem sido, historicamente, orientada a partir do uso de estratégias individuais associado à assimilação dos códigos e valores gerados e mantidos, no entanto, pelo brancocentramento do poder dominante. Ora, ao negro brasileiro, embebido pelos discursos de neutralidade racial e econômica, restou comprar os valores da sociedade branca como um importante elemento para conseguir uma melhoria na sua posição socioeconômica. Justamente por conviver em uma sociedade em que o racismo acontece e é veemente negado, o negro brasileiro teve que disputar com os profissionais brancos espaços de poder e de representação. Nesse sentido, os negros tiveram que, historicamente, assumir o ônus da estrutura racista brasileira que limitava suas possibilidades, utilizando estratégias de maior solidariedade com a ideologia da miscigenação e menos com um antagonismo racial que seria mais lido como um racismo às avessas do que como uma luta por redistribuição (CASTRO, 2017; SOARES, 2004).

As estratégias de mobilidade socioeconômica da população negra média brasileira, portanto, tem circulado entre um grande investimento na educação formal de seus familiares, pelo emprego público, pelo apoio da rede familiar e, acima de tudo, por escolhas cuidadosas negros não podem se dar ao luxo -, dentro das reais possibilidades de êxito. No Brasil, nos últimos anos identificamos um grupo de negros de classe média e esse fato dificulta versar sobre o mesmo como membro da elite política e econômica, seja em relação à sua posição 
instável ou incipiente na classe média, seja no que tange à ausência de sua representação política (ANDREWS, 1997, 2007; FIGUEIREDO; FURTADO, 2014; SANTANA, 2014).

Nesse cenário, portanto, o projeto familiar de ascensão dos negros foi feito sobre o sacrifício e renúncia da geração de negros passados para construírem realidades diferentes para os jovens negros de agora. É possível afirmarmos que essas novas famílias negras migraram de classe em um curto espaço de uma geração, experimentando uma ascensão social sem precedentes do ponto de vista sócio-racial nas instituições em que atuam como também no próprio meio familiar. Os filhos dessa atual geração de negros ascendidos disputam, atualmente, o espaço da universidade pública - junto aos negros pobres -, também, como modo de garantir o conquistado diploma da classe média e dar continuidade ao processo de estabilidade econômica e reconhecimento acadêmico outrora conquistado. Quais são as implicações desses processos de mobilidade, em direção à classe média universitária, diante de um cenário do debate racial mais amplo e de um possível novo futuro para o ensino superior público? (RODRIGUES et al., 2006; ANDREWS, 1997, 2007; SANTANA, 2014).

Para Chauí (2004), existe uma classe média já consolidada, que vende a ideologia que alcança todos os setores da sociedade. Valores como o individualismo, a competição, o sucesso a qualquer preço, o isolamento e o consumo são propagados como projetos de vida e de sociedade únicos e totais. O diploma universitário, nesse contexto, é o exemplo clássico do que se torna um projeto de vida e um meio para as conquistas no mundo do consumo. Essa classe média, segundo a autora, é a que sempre existiu, tendo de novo, apenas o seu crescimento quantitativo e de seu poder econômico em tempos atuais. É justamente essa nova classe média estabelecida e poderosa que, embebida em um projeto brancocentrado e elitista, torna a universidade um dispositivo ideológico de sua conquista e da propagação de seus valores como verdades, em detrimento do reconhecimento de outros modelos de vida (OLIVEIRA SARAIVA, OLIVEIRA REZENDE, SOUZA REIS, INÁCIO, 2015)

A ideologia da classe média mais tradicional, nesse sentido, seria justamente a intenção e ação que tomam suas ideias como independentes da realidade histórica e social, de modo a fazer com que tais fundamentos expliquem naturalmente alguma realidade que, comumente, é um ponto de vista das classes médias brancas.

Isso porque os negros que ascendem não constituem um grupo hegemônico com interesses específicos de classe vinculados a demandas raciais. A mobilidade individual dessas pessoas e de seus familiares dificulta a consolidação de uma classe média negra no sentido de uma pertença de classe com interesses, demandas e lugares semelhantes; o que 
dificulta a constituição de ações coletivas, em defesa de interesses do grupo e com fundamento no pertencimento negro (SANTANA, 2014).

Nesse sentido, não seria a entrada de negros, na classe média, um potencial ampliador de discursos distintos dos brancocentrados? A existência de negros de classe média não colaboraria para a pluralização de mais trajetórias negras em lugares, historicamente, brancos? Não teria a entrada dos negros, nos setores médios econômicos e na universidade, a capacidade de criar fissuras em discursos brancos e elitistas que se propagam como verdades/conhecimentos totais da classe média universitária?

\section{Ações Afirmativas: uma proposta afirmativa contra hegemônica ao racismo e/ou ao classismo?}

Reconhecemos, em linhas gerais, uma maior utilização e comercialização de símbolos, conhecimentos e produtos da denominada cultura afro-brasileira, assim como o surgimento de uma ampliação da pertença e práticas negras, nas últimas décadas; o que tem atingindo negros de classe média, e criam, provavelmente, algumas condições para que esses sujeitos produzam posições entre ser negro e ocupar posições mais valorizadas na hierarquia social e econômica. Nessa direção, no Brasil, há grupos que, historicamente, excluídos da universidade, tem-na acessado atualmente. O número de negros no espaço da universidade tem aumentado, sobretudo pela implementação de políticas de ação afirmativa. E, sendo assim, essa instituição vem lidando com um espaço em que antes, a negritude tinha um lugar apenas marginalizado (FIGUEIREDO, 2002; GOMES, 2017).

Ainda com a toda a polêmica envolvida nessas políticas ${ }^{4}$, os dilemas atuais das cotas e das ações afirmativas se estendem para além de sua viabilidade. Uma vez institucionalizada federalmente, o problema agora se volta, principalmente, para a garantia da permanência desses estudantes na universidade pública, na reorganização dessas intuições para receber esse público, bem como para o seu acesso a pós-graduações e ao mercado de trabalho (MAYORGA; SOUZA, 2012). Na história afirmativa dos Estados Unidos, é devido a essas políticas que se deve o crescimento da classe média negra; da representação mais enegrecida no Congresso Nacional e nas Assembleias Estaduais; aumento de estudantes e professores negros nas universidades; bem como mais profissionais negros de prestígio em todos os setores da sociedade americana. O que, por sua vez, mostra-nos um cenário positivo, nas

\footnotetext{
${ }^{4}$ Para mais informações, ler Sito, L. (2014). Disputas e diálogos em torno do conceito de "ações afirmativas" para o ensino superior no Brasil. universitas humanística, (77), 251-273.
} 
últimas quatro décadas, dos países que implementaram ações afirmativas. Esse cenário de democratização estadunidense pode ser tomado, então, como um horizonte ético diante de políticas específicas que visam à democratização da sociedade e servem, ao Brasil, como exemplo do possível (GUIMARÃES, 2003; AZEVEDO, 2004; MUNANGA, 2001; SITO, 2014; FERES JÚNIOR DAFLON; LERNER, 2015).

No entanto, de modo algum, podemos tomar a experiência da política afirmativa estadunidense como um dispositivo emancipatório que se aplique diretamente ao Brasil. Até porque, no caso, brasileiro, a dinâmica do racismo e, também, a política universitária antirracista terminaram por se organizar de formas muito distintas.

Com isso queremos dizer que o Brasil e os EUA possuem diferenças analiticamente perceptíveis, respectivamente, à saber: quanto ao modo de atuação do racismo (preconceito de marca, cor X preconceito de origem); quanto à definição de raça/cor (autodesignação $\mathrm{X}$ heterodesignação); quanto ao caráter do racismo (ambíguo/cordial X explícito) ; quanto ao efeito do racismo nas relações interpessoais (tolerância $\mathrm{X}$ conflito); quanto ao dispositivo ideológico da miscigenação (somos todos iguais X somos racialmente diferentes) e, por fim, quanto aos aspectos estruturais socioeconômicos (preconceito de raça disfarçado sob o de classe $\mathrm{X}$ impermeabilidade que se observa entre os grupos branco e negro independentemente da classe) (NOGUEIRA, 2007) .

No caso brasileiro, por exemplo, essas divergências estruturais, históricas, políticas e econômicas em relação ao dinamismo do racismo e ao seu combate terminaram por gerar uma política afirmativa que prevê a reserva de $50 \%$ das matrículas por curso e turno nas universidades federais e nos institutos federais de educação, ciência e tecnologia a alunos oriundos integralmente do ensino médio público, em cursos regulares ou da educação de jovens e adultos. O que denota uma preocupação explícita do governo brasileiro com o combate a defasagem de formação dos alunos das escolas básicas públicas brasileiras em relação aos alunos com trajetórias em escolas privadas. Entre as vagas separadas pelo critério de renda, a distribuição das vagas da cota racial é feita de acordo com a proporção de índios, negros e pardos do Estado onde está situado o campus da universidade, centro ou instituto federal, segundo dados do Instituto Brasileiro de Geografia e Estatística (IBGE).

Comparando o contexto histórico em que as políticas de ação afirmativa passaram a ser implementadas nas universidades norte-americanas a partir do final da década de 1960, com o atual contexto brasileiro, em que as primeiras experiências vêm sendo realizadas, início do século XXI, existem aspectos diferentes que convêm salientar. O movimento negro e o movimento pelos direitos civis nos Estados Unidos foram influenciados pelas lutas de libertação das colônias africanas e asiáticas do jugo europeu. O discurso era o da cidadania, da libertação e constituição de novas nações independentes. Nesse mesmo período, a ideologia da 
democracia racial no Brasil não tinha sido fortemente questionada por dados de pesquisas, que passaram a mostrar, de forma mais contundente, a desigualdade entre brancos e negros e o preconceito racial na sociedade brasileira. $\mathrm{O}$ debate sobre as ações afirmativas, principalmente aquele referente a cotas nas universidades brasileiras, embora tenha um marcado cunho nacional, acontece numa outra conjuntura em termos mundiais. Ele se pauta num discurso mais amplo de inclusão de grupos discriminados expresso em protocolos internacionais, assinados pela maioria dos países do mundo, inclusive o Brasil. Tem muito a ver com a visão dos direitos humanos, do direito ao reconhecimento do valor de cada cultura e do respeito à diversidade (OLIVEN, 2007, pp. 48-49)

As cotas universitárias, portanto, complexificam o debate das ações afirmativas no Brasil. Por um lado, comemora-se a sua vitória e os seus efeitos imediatos na atmosfera pública e dos direitos; por outro, novas perguntas e problemas surgem. As tensões que envolvem os sistemas de poder que marcam a história do Brasil ainda não são consenso na literatura acadêmica do pensamento social brasileiro. Com isso queremos dizer que há algumas posições que discordam da leitura de que as lógicas raciais são estruturais na dinâmica da desigualdade brasileira e, portanto, essas visões combatem a ideia de que a raça seja um critério relevante para se pensar políticas afirmativas. Nessas leituras, a visão de classe prevalece (MAGGIE; FRY, 2004; SANSONE, 2000; SOUZA, 2000, 2005). Ainda que esses autores não neguem o racismo, de fato, eles não acreditam que a política afirmativa teria a potência de combater o racismo brasileiro; mas de cindir e racializar uma nação que possui um grande potencial em direção a uma pertença miscigenada.

Por outro lado, há outros discursos, em disputa, que compreendem que os sistemas de poder de raça e de classe, ainda que intimamente relacionados, operam em lógicas de produção de hierarquias distintas. Esses pensamentos enfatizam o preconceito e a discriminação racial como um sistema de poder que opera aproximando-se e afastando-se dos sistemas de classe. O argumento central desse pensamento defende a tese de que as desigualdades brasileiras apresentam um componente racial inequívoco, que não poderia ser reduzido às diferenças de educação, renda e classe (GUIMARÃES, 1999, 2016; FERES; DAFLON, 2015).

Em suma, há uma disputa em torno da prática das ações afirmativas que apontam para as diferentes maneiras de conceber a identidade nacional brasileira: uma maneira mais antiga, associada a mitos fundacionais de unidade baseados nas supostas virtudes da mistura racial e, apenas, na existência de desigualdades econômicas; e uma nova, baseada nas noções democráticas de equidade de oportunidades e direitos no âmbito racial. Ou seja, há posições que compreendem a desigualdade racial como sendo reduzível aos problemas econômicos, bem como outra visão que reforça a especificidade do racismo à brasileira e, portanto, politiza o direito dos negros, bem como reivindica a negritude como uma postura e posição 
antirracista (SCHWARTZMAN; SILVA, 2012)

Nessa direção, parece-nos que a utilização de cotas e de uma política afirmativa radical que lide com problemas nodais (raciais e econômicos) da história brasileira não só garante uma trajetória acadêmica bem sucedida para negros e populares; mas desconstrói pilares tão engessados em uma instituição como a universidade pública: "tanto os elementos dos quais lançamos mão para estabelecer os critérios da meritocracia, a dinâmica institucional burocratizada, quanto às concepções de ciência hegemônica presentes na universidade" (MAYORGA E SOUZA, 2012, p.279).

Estamos falando aqui, portanto, de possíveis viradas epistemológicas em relação ao tratamento dado a como a política de ação afirmativa é aplicada ao contexto brasileiro, já que aqueles que outrora foram os objetos de estudo e visto como as vítimas que precisavam de políticas assistencialistas - estritamente econômicas -; hoje, a partir da ação afirmativa, podem produzir posições e lógicas menos assujeitadas. O alcance político e transformador das políticas afirmativas precisa, de fato, ser potencializado. Isso só pode ser feito, a nosso ver, com a inclusão de outros marcadores sociais - que não só classe - como um dos elementos norteadores de uma política que visa combater desigualdades históricas, na qual as experiências de racismo e de pobreza ora se aproximam, ora se afastam (AGUIAR, 2007; SCHWARTZMAN, 2009)

Isso significa que para que ação afirmativa não tenha efeitos perversos, devemos pensar as desigualdades de raça e classe como experiências que vão além daquilo que "limitam" alguns sujeitos. É importante se fazer perguntas maiores cujas respostas, certamente, ainda precisam ser produzidas: qual o objetivo das universidades públicas? Qual a potência e a contribuição dos saberes negros e populares para a universidade? Há, nessa problemática, muitos dilemas éticos e políticos que apontam para qual modelo de sociedade e, nesse caso, universidade queremos ser. "Enquanto não ficar claro o compromisso do governo com a expansão da pesquisa científica, nessas universidades, qualquer movimento no sentido da flexibilização do acesso pode ser mal interpretado (...) a comunidade científica pode continuar a dar de ombros e dizer que esse não é o seu problema?” (GUIMARÃES, 2003, p. 266).

O objetivo, aqui, não será jamais o de esgotar o amplo e complexo debate das ações afirmativas e das cotas universitárias. Primeiro porque a busca por uma categorização única desse conceito não nos parece ser uma boa saída teórica e política; e segundo porque não haveria espaço, aqui, para que pudéssemos desenvolver o problema das políticas afirmativas 
em sua ampla matiz. Nesse sentido, é primordial que possamos observar que a disputa em torno do sentido e da funcionalidade dessas políticas é de extrema importância para que possamos reconhecer os distintos posicionamentos que existem no contorno da democratização do ensino superior público e das produções científicas (SITO, 2014).

Levando-se em consideração as discussões levantadas nesse artigo, o jogo da disputa no campo da ciência representa e manifesta as relações desiguais entre os brancos e os negros no contexto brasileiro. Bem como, explicitam que as condições de realização das atividades propriamente científicas - a própria definição de ciência, a legitimação de seus paradigmas, métodos e teorias que podem ser considerados científicos - vão ao encontro dos interesses específicos dos grupos brancos e ricos que detém, em maioria, o poder no campo acadêmico. Trazer as ações afirmativas, nessa pesquisa, portanto, significa pensá-las enquanto um projeto que resiste ao brancocentramento e ao elitismo como norma de organização da sociedade, do conhecimento e das universidades (BOURDIEU, 2003; GROSFOGUEL, 2016; TAFURI, 2011)

\section{Metodologia: caminhos da pesquisa}

Em diálogo, com preposições que compreendem a complexidade de um processo investigativo no campo do debate das relações raciais e da democratização do ensino superior público no Brasil, adotamos o campo das narrativas como o aporte epistêmico e metodológico dessa pesquisa. As narrativas são o efeito da relação entre a estrutura social e o mundo idiossincrático dos desejos, das crenças e das esperanças. Sendo assim, ao contarem as suas histórias, os indivíduos não pretendem, somente, memorizar e reelaborar suas experiências: eles, também pretendem, explicitamente, posicionar-se diante de suas histórias; convencendo, persuadindo e impressionando os seus interlocutores (CLANDININ; CONNELLY, 2011; FONTE, 2006).

$\mathrm{Na}$ escolha pelos relatos narrativos, portanto, deixamos de coletar produções de fatos individuais e estamos interessados na interpenetração entre sujeito e história, bem como entre os acontecimentos, as leituras e as interpretações que os sujeitos fazem de si mesmos e dos outros. A análise das narrativas é, sobretudo, possível dentro de uma situação comunicativa e, nesse sentido, o sujeito narra sua história de vida; descrevendo situações e argumentando sobre problemas significativos e recorrentes em sua vida e como ele se relaciona com isso. $\mathrm{O}$ pesquisador, nessa direção, ao operar com esse material comunicativo, torna-se, imediatamente, ele mesmo um interlocutor, integrando o circuito dialógico da produção do 
conhecimento (CARVALHO, 2003; CASTRO; MAYORGA, 2018)

O uso das narrativas na investigação dos universitários negros de classe média dessa pesquisa foi, definitivamente, uma estratégia de interação e organização das falas dos sujeitos que lançasse luz aos problemas, aos conflitos e às elaborações que esses sujeitos fazem sobre seu lugar social e suas experiências, a partir de suas compreensões sobre a democratização do ensino superior público (CASTRO; MAYORGA, 2017). Nessa direção, para a coleta e interpretação dos dados, para esse artigo, lançamos mão da construção das narrativas com quatro sujeitos negros - de distintos campos e áreas de conhecimento e atuação em alguma forma de participação política antirracista -, com trajetórias acadêmicas na UFMG, autodeclarados pretos e que foram convidados a falar da/pela/para/contra a classe média/classe média negra ${ }^{5}$, a saber ${ }^{6}$ :

\section{Dandara}

É graduanda do curso de Ciências Sociais da UFMG. Tem 23 anos, solteira. Foi escolhida por mim em reunião de orientação como uma sujeita potente para uma conversa sobre o campo-tema de pesquisa. Dandara é filha única de um casal interracial: pai negro engenheiro (graduado na fase adulta) concursado e mãe branca auxiliar de enfermagem. Mora em um bairro periférico da Zona Norte de Belo Horizonte. Dandara foi graduanda do curso de Ciências Sociais, abandonou o curso em 2013 e mudou para Arquitetura em uma universidade privada. Em seguida, segue para um Instituto Federal e, por fim, retornou às Ciências Sociais na UFMG. Estudou em escola pública até a quarta série do ensino fundamental. Em seguida, mudou-se para um colégio particular de um bairro periférico de Belo Horizonte onde terminou a sua escolaridade até entrar na UFMG sem o uso das ações afirmativas. Atua em uma Frente Feminista Negra universitária e em um coletivo de incentivo, produção poética, difusão e declamação de literatura negra feminista.

\footnotetext{
${ }^{5}$ Pesquisa aprovada pela COEP. CAAE- 57289516.6.0000.5149

${ }^{6}$ Todos os nomes fictícios foram retirados de figuras negras (pretas e pardas) históricas relevantes no contexto brasileiro, a saber: Dandara, uma guerreira negra do período colonial do Brasil, esposa de Zumbi dos Palmares. Gilberto Gil, músico brasileiro, conhecido por sua inovação musical e participação como Ministro da Cultura. Milton Nascimento, cantor e compositor brasileiro reconhecido mundialmente como um dos mais influentes e talentosos cantores e compositores da Música Popular Brasileira. Por fim, há Nilma Lino Gomes, também exministra, que se tornou a primeira mulher negra do Brasil a comandar uma universidade pública federal, ao ser nomeada reitora da Universidade da Integração Internacional da Lusofonia Afro-Brasileira (UNILAB).
} 


\section{Gilberto}

É graduando do curso de Ciências Socioambientais da UFMG. Tem 22 anos, solteiro, e foi indicado para essa pesquisa por um amigo próximo. Gilberto tem em seu núcleo familiar a mãe e a tia: duas mulheres negras que vieram do interior de Minas Gerais para Belo Horizonte estudar. Sua mãe formou em Terapia Ocupacional na UFMG (aos 30 anos de idade) e é concursada. Gilberto é nascido em Belo Horizonte, mas passou grande parte das férias da infância na região rural de sua família materna. Hoje, ele mora em um bairro da região nordeste da capital mineira com a mãe e a tia, mas já morou em vários e distintos bairros e casas da cidade. Estudou em escola pública um pequeno espaço de tempo e fez a maior parte da sua escolaridade no ensino privado antes de entrar na UFMG. Não fez uso das ações afirmativas e cotas. Atua no cenário da movimentação Hip Hop, sendo rapper e participando de vários duelos de Mcs (Mestre de Cerimônias)

\section{Milton}

É professor da rede pública de Belo Horizonte e analista de políticas públicas. Possui graduação em Ciências Sociais na UFMG. Tem 29 anos, solteiro e foi indicado para essa pesquisa por uma colega da pós-graduação da Psicologia. Milton é filho de dois negros profissionais liberais, ambos com ensino superior público. Seu pai, de uma família de uma cidade muito pequena do interior de Minas, foi adotado por uma família branca e é engenheiro civil. Sua mãe (nascida na região metropolitana de Belo Horizonte) é administradora de empresa e possui o próprio negócio. Seus pais foram militantes do Movimento Negro Unificado na capital mineira. Seu núcleo familiar principal é formado por seus pais, dois irmãos e uma irmã. Todos são negros. Dois são engenheiros (Civil e de Minas). A irmã está concluindo o curso de Arquitetura em uma universidade privada. Antes de sair da casa de seus pais, Milton morava em um bairro da região da Pampulha. Hoje, vive em um apartamento na zona sul de Belo Horizonte. Milton trabalhou como técnico de turismo durante um ano, em outra cidade, antes de ser aprovado no vestibular para Ciências Sociais. Estudou em escola particular de primeiro grau, no ensino médio público e, por fim, no ensino médio técnico federal antes de entrar na UFMG. Em sua época de entrada na graduação, não havia ações afirmativas e nem cotas. Tem atuado em um bloco de carnaval com temática afroreferenciada e em um grupo de dança africana. 


\section{Nilma}

É graduanda do curso de Ciências Socioambientais da UFMG e auxiliar administrativa (terceirizada do estado). Tem 28 anos, solteira e foi indicada para essa pesquisa por um amigo próximo. Seu pai (pedreiro aposentado e atual bombeiro hidráulico) e sua mãe (auxiliar de serviços gerais- cantineira), ambos negros, são provenientes da região do Jequitinhonha em Minas Gerais. Seus pais se conheceram na região metropolitana de Belo Horizonte e se transferiram para uma cidade mais próxima da capital quando ganharam uma casa devido a um programa do governo federal. Possui uma irmã graduada em uma universidade estadual, mas que ocupa um cargo de secretária enquanto não consegue um emprego na área. Uma outra irmã formou no ensino médio e encontra-se desempregada. A irmã mais velha casou-se e saiu de casa. Uma vez formada no ensino médio, Nilma passou em um concurso e, até então, ocupa tal cargo. Antes desse emprego, trabalhou seis meses em telemarketing. Em seguida, estudou em cursinho preparatório para vestibular e foi aprovada no curso de ciências socioambientais após tentar por dois anos ingressar no curso de Direito da UFMG. Estudou integralmente em escolas públicas e, por isso, mesmo fez o uso das ações afirmativas para estudantes negros e oriundos de escola pública. Atuou em uma Frente Feminista Negra Universitária.

Se, por um lado, contamos com a autodeclaração racial para encontrar sujeitos negros; por outro, não intencionamos produzir nenhuma exegese conceitual em relação à classe. De modo que sustentamos a nossa visão entendendo a classe média e o surgimento dessa nova não só como um elemento empírico; mas como um dispositivo que organiza vidas e instituições.

Consumo, trabalho, acesso a bens, serviços, espaços da cidade; mudanças que também afetam não apenas quem pode ascender socialmente, como aqueles que passam a, de maneiras diversas, conviver com essas pessoas. Isto é, nomear alguém como "nova classe média" implica intensos efeitos em toda nossa sociedade. Verdadeira ou não, a "nova classe média" fala de um fenômeno real, isto é, que aciona realidades, produzindo novas formas dos sujeitos consumirem, morarem, vestirem-se, novas possibilidades de acesso a bens e serviços, novos desejos, modos de entender a si mesmo, os outros e o mundo e de se relacionar, consigo e com os outros (OLIVEIRA SARAIVA et al, 2015 p 59)

\section{Ações Afirmativas - Narrativas Enegrecidas e Economicamente Médias: um novo projeto de sociedade/universidade?}

O assunto das cotas e demais ações afirmativas não são, de maneira alguma, um assunto sem conflitos. Não há qualquer consenso acerca da funcionalidade ou da legitimidade 
dessas políticas. Questionar esse tema a negros universitários de classe média nos revela algumas incongruências e apontam para uma série de melhorias que as ações afirmativas precisarão ter nos próximos anos. Ainda com as devidas críticas a essa política; a denúncia da ausência histórica de negros na UFMG é narrada, expressivamente, não como um infortúnio aleatório, mas como um projeto de sociedade/universidade racista e classista. Sendo assim, o que mais nos chamou a atenção foi como essa posição favorável às ações afirmativas é construída a partir de lugares, concepções e experiências distintas (FERES; DAFLON, 2015).

Dandara: a cota ela é uma ferramenta, um mecanismo viabilizador disso também, de ocupar espaços que são nossos, mas que são negados por várias gerações, então elas podem ser a ferramenta da próxima geração ser diferente (...)

Gilberto: É... ahhh... E eu acho que as ações afirmativas é... age muito nesse ponto (...) primeiro de mostrar para algumas pessoas que isso é possível, segundo de viabilizar isso de certa maneira, saca?

Milton: então essa reparação que se faz ela é necessária, né? E é algo que talvez seja muito mais simples que a gente pensa assim, as pessoas gostam de criminalizar a situação e querer inverter a lógica como se isso fosse um racismo ao inverso (...) os negros vão disputar em pé de igualdade (...) as ações afirmativas elas tem essa tendência de reconfigurar esse fato social. Então, eu sou extremamente favorável tendo em vista que, por exemplo, que eu poderia ser um cara ao contrário disso porque eu consegui todas as coisas, mas sabendo que eu tive uma situação de privilégio em relação população negra brasileira (...)

$\mathrm{Na}$ direção da falta de representatividade negra nos espaços de poder e saber da universidade, os sujeitos apontam para um perigo do conhecimento, no Brasil, ser produzido a partir de referenciais, unicamente, brancocentrados e europeus (BERNARDINO-COSTA; GROSFOGUEL, 2016).

\begin{abstract}
Milton: eu sou muito ligado com a cultura popular, com a educação popular, e toda aquela excelência acadêmica que se preza na UFMG dentro de um padrão europeu ocidental, me deixava com poucas vontades de estar ali.

Nilma: Na universidade não tem um debate tão claro assim, não tem, recorte racial (...) então quer dizer, eu sou negra, eu moro na periferia, e eu sofro com várias questões raciais (...) e não tem esse debate, isso eu acho que é uma falha, assim.
\end{abstract}

Com essas falas, evidenciam-se os processos sob as quais os negros tiveram que, historicamente, ocupar na interação com os setores médios e da elite intelectual brasileira: o lugar abjeto (na produção do racismo científico da modernidade que desumanizou as populações afro-brasileiras) ou o lugar de objeto de estudo do campo científico (na perspectiva de um outro exótico que necessitava ser analisado) (SKIDMORE, 2013) Hoje, esses sujeitos reivindicam seus lugares na produção do conhecimento como autores; como sujeitos capazes de teceram análises, críticas e construções de conhecimento sobre si e sobre o 
mundo. Algo que foi, durante muito tempo, um lugar sagrado de produção, apenas, das elites brancas. (SCHUCMAN, 2012).

\begin{abstract}
Dandara: A gente (negros) é o objeto de estudo desse lugar... quem tem que tá falando por mim aqui? Eu tenho que falar por mim aqui, eu tenho que escrever sobre mim aqui, isso me incomodava, mas eu não conseguia verbalizar isso de uma maneira que eu pudesse transformar isso em algo que eu não sofresse tanto, entende? (...) E essa coisa né de achar que você tá, é como se você tivesse levando a luz a alguém, isso me incomoda muito essa relação aqui.

Gilberto: E eu e mais alguns outros alunos negros do curso que tivemos que levar isso para a discussão em sala de aula assim. Por parte dos professores isso não acontece. Embora sempre seja discutida a questão dos quilombos, é... sempre seja discutida várias questões assim que perpassam a questão racial, nunca é colocada diretamente essa questão da... da negritude, da raça também. É bem... é, não sei se é só uma escolha acadêmica dos professores!
\end{abstract}

O epistemicídio é a atividade sistemática de negação do saber dos povos e comunidades tradicionais, o que tem como efeito relações de poder que mantém o domínio intelectual e cultural da supremacia branca. Na direção contrária, um conjunto de pensamentos contra hegemônicos têm apontado para a importância de se construir epistemologias de resistência que interpelem o paradigma epistemológico da ciência moderna/branca/europeia. As ações afirmativas parecem corroborar, nessa direção, quando trazem à reflexão epistemológica o contexto cultural e político da produção e reprodução do conhecimento. Quais foram as consequências de tal descontextualização na produção do saber científico canônico? Um branqueamento epistemológico? São hoje possíveis outras epistemologias? (SANTOS, 2002; LIRA; TRINDADE, 2016)

É notável, no entanto, uma forte tensão que existe em estar em um local, historicamente, brancocentrado e que, por outro lado, esforça-se em repensar a sua relação com os saberes e a cultura negra. Há paradoxos, até mesmo, na boa vontade daqueles atores universitários que convocam a enunciação pública dos acadêmicos negros.

Gilberto: Quando que vem algum negro falar de alguma questão aqui, alguma pauta na UFMG que não seja sobre racismo, ou cultura negra, ou quilombos, saca? Tipo assim já tem um lugar certinho assim pros negros aqui dentro dessa instituição. Tipo assim... Ah não semana da consciência negra chama fulano de tal (...) para discutir meio ambiente, para discutir comunicação, para discutir psicologia onde é que estão os negros, saca? Isso não acontece. E tem muita gente capacitada por ai para falar desses assuntos sabe. É... então é... e também às vezes é colocado muito só na questão da cultura, saca?

Gilberto questiona o convite da universidade e de universitários solidários a causa antirracista: qual espaço eles têm convocado os negros a ocupar? Nesse sentido, Gilberto nos provoca a pensar sobre um dilema que tangencia a discussão acerca do lugar de fala dos 
negros. Vejamos: ainda quando a universidade compreende a importância dos saberes e das práticas das populações negras, esse convite pode incorrer em um erro comum no qual os negros só possam falar sobre temas raciais e/ou culturais. Ora, quando os negros entram na universidade pública, compreendemos que junto com eles há uma bagagem cultural, política e econômica, mas também intelectual, que começa a fazer parte da universidade. Nessa direção, é importante que os sujeitos negros universitários possam mostrar a sua arte e a sua cultura; mas que, também, possam existir como produtores e coautores de conhecimentos em distintos campos do saber (CARVALHO, 2012; RIBEIRO, 2017)

\begin{abstract}
Gilberto: quais espaços nós estamos falando, sabe? Tipo assim, é... tipo eu não quero vir aqui só para sei lá, quando tem uma batalha, manda uma rima aí, canta, geral bate palma. Isso não velho, saca? Não são só esses espaços tipo assim. Nós queremos ocupar inclusive os espaços de poder. Não espaço do espetáculo, saca? Para a galerinha ficar batendo palma. Não! Nós queremos reitores negros, saca?
\end{abstract}

Há um claro interesse, aqui, em provocar furos na ideia de uma modernidade que só foi possível e acessível à elite branca. Isso significa romper com referenciais brancocentrados de organização da vida privada e pública moderna. Os universitários não acreditam que a negritude deva se essencializar em uma África mítica e tribal - essencialmente cultural -, mas em referenciais afrocentrados que possam existir em espaços de poder, historicamente, brancos. Os processos ascensionais sócio-raciais, ocorridos não só no Brasil, mas em outros lugares do mundo, levaram, inclusive, a uma globalização e a uma internacionalização do banco de símbolos nos quais as culturas negras podem buscar inspiração. De modo que seja possível observar, na população negra, um grupo intelectual que está se tornando visível e que possui demandas e proposta de ação-intervenção nos espaços do ensino superior público (PIRES, 2014)

Esses universitários negros de classe média têm se sentido desconfortáveis com as construções tradicionais da negritude como um fenômeno da classe baixa, além da caracterização dos negros como indivíduos incapazes de serem inteligentes, consumir com status e requinte de refinamento. Afinal, resistir ao brancocentramento em nada tem a ver com abrir mão da excelência acadêmica e intelectual das populações negras; mas, sobretudo potencializar a construção de um saber que seja coletivo, potente, transformador e que tenha como defesa a diversidade como elemento constituinte da educação. Aqui, os negros recusam a incorporação de normas e valores brancocentrados como caminho único para obterem o estimado êxito acadêmico e, muito pelo contrário, reivindicam a negritude dentro do campo do saber (CARTER, 2005). Nesse sentido, observamos uma disputa pela redefinição do 
pertencimento negro, dado que, ainda que os estereótipos raciais determinem que negros estejam em atividades e lugares desprestigiados; hoje, vários deles querem e participam de espaços economicamente médios e de poder, como a universidade pública. Algo que foi, potencializado, nas trajetórias de alguns, por acessos e privilégios efeitos de uma educação e de uma socialização garantidas por ganhos econômicos de suas famílias (SANTANA, 2014).

Nessa direção, não raramente, os negros de classe média são elencados como exemplos de que as ações afirmativas não deveriam existir, afinal, nesse pensamento, seria possível alcançar a vaga superior pública sem a ajuda de uma prática discriminatória positiva.

Milton: eu sou o tipo do cara que os movimentos conservadores adoram e debruçam em cima com muita força, o que eles consideram como bode expiatório; que eu sou um cara que talvez não precise de nenhuma política afirmativa. (...)

Há toda uma tensão que aponta para o perigo das ações afirmativas beneficiarem, apenas e, sobretudo, os negros de classe média e, portanto, passíveis de construir elites intelectuais e econômicas negras ao invés de combater o racismo estrutural do Brasil. A ação afirmativa, a partir das narrativas elencadas acima, parece ser vista, portanto, como uma política socioeconômica, direcionada a negros pobres; mas, também, como dispositivos que gerem oportunidades para a classe média negra, aumentando a diversidade representativa na elite brasileira (SCHWARTZMAN; SILVA, 2012)

Milton: E eu acho que, por exemplo, eu vou tá sendo contemplado por uma reparação histórica coletiva

Ainda que essa seja a construção de uma posição difícil - dada a operacionalidade do mito da democracia racial que, muitas vezes, subalterniza as questões raciais à de classe alguns universitários negros estão implicados em um reconhecimento do sistema racial como sendo um sistema independente - e não isolado - do sistema de classes e, por isso mesmo, ainda que advindos de famílias com dinheiro; esses estudantes compreendem as ações afirmativas como ferramentas antirracistas para todo e qualquer sujeito com fenótipos negros. O que aponta, também, para o fato de que alguns negros universitários de classe média têm coletivizado suas trajetórias de ascenção e recusado vive-las, apenas, sob a ótica do mérito individual. Em linhas gerais, os sujeitos, ainda aqueles não assistidos pelas cotas, sentem-se representados pela política afirmativa ao localizarem-na numa conquista coletiva independentemente de que sejam eles próprios os beneficiários (AGUIAR, 2007; SCHWARTZMAN, 2009)

Nessa direção, os sujeitos defendem as políticas afirmativas enquanto um projeto da universidade e da sociedade que deveria reverberar de distintas maneiras para além da reserva 
de vagas aos negros. Apontando para a importância, por exemplo, de que essas políticas coexistam com outras propostas de transformação antirracistas que, inclusive, tenham como preocupação central o sucateamento das escolas públicas e o genocídio da juventude negra e pobre (CHAUÍ, 2003; NASCIMENTO, 2016)

\begin{abstract}
Nilma: eu acho que as cotas são importantes sim. Só que não só investir em cotas né, eu acho que tem que melhorar a educação também. Só investir no ensino superior se os jovens não tão chegado aqui, se eles tão sendo mortos antes? Às vezes a população não tá chegando nem no ensino médio, quem dirá na faculdade (...)

Gilberto: Mesmo que a política é... não seja tão é... não tenha tanta capilaridade, ou seja, não tão expandida quanto a gente gostaria que ela fosse, é... só dessa forma que ela já é, já possibilita algumas pessoas... Que no futuro podem desencadear várias outras mudanças, saca? Eu penso assim (...) primeiro de tudo você precisa ter acesso a uma determinada linguagem e ter acesso a alguns mecanismos para acessar a própria política de cotas. E isso nem todas as pessoas tem, assim...
\end{abstract}

Seja na construção das ementas das disciplinas, nas maneiras de organização e construção dos saberes, na interação com a sociedade; na relação com outros graus do ensino público; esses sujeitos denunciam a ausência epistemológica de negros como sujeitos e agentes da sociedade e, também, da universidade. Essas narrativas apontam para como é necessário pensar sobre qual projeto de sociedade e universidade as ações afirmativas e as cotas podem nos ajudar a caminhar na direção de uma verdadeira democracia racial no Brasil. Uma democracia onde a história branca - e tudo associada a ela - seja, apenas, mais um lugar histórico e não a norma de organização dos poderes e dos saberes a partir de uma proposta universal da vida (BERNARDINO-COSTA; GROSFOGUEL, 2016; LIRA; TRINDADE, 2016).

É preciso, nessa direção, alterar as relações socioeconômicas, os padrões culturais, as referências sócio-raciais e as formas de produzir e reproduzir a história e o conhecimento brasileiro. Existe um conjunto de leis antirracistas disponíveis que precisam ser mais, estratégica e politicamente, executadas como forma de interpelarem pilares basais de organização das nossas ações educacionais e intelectuais que operam e transformam o mundo. A Lei 10.639, por exemplo, possui uma potência e uma importância radical na medida em que altera a Lei de Diretrizes e Bases da Educação Nacional (1996) e torna obrigatório o ensino sobre História de Cultura Afro-brasileira (história da África e dos africanos, bem como a luta e resistência dos negros no Brasil) nos estabelecimentos de ensino fundamental e médio, oficiais e particulares.

Milton: Então assim, nesse sentido, a gente tem que ser crítico, né? Eu, realmente, gostaria que a gente tivesse um acesso a educação sem que você fosse medido por uma prova. A prova não qualifica quem é melhor ou pior aluno, né? Só quem tá mais preparado pra aquele tipo específico de prova, aí tá condensado num esboço ali já dado, né? Então, se eu pudesse eu 
faria uma reforma educacional onde não precisasse disso e onde o mérito não fosse uma questão primordial né, e que os jovens tivessem uma gama de escolhas....

Em linhas gerais, os sujeitos pontuam que a universidade tem, historicamente, cumprido o papel de legitimação de desigualdades - ao dissimular as suas bases sociais e políticas elitistas e raciais - convertendo-as, perversamente, em diferenças acadêmicas e cognitivas, relacionadas aos méritos e aos dons individuais dos sujeitos. Nessa direção, os universitários negros de classe média parecem discordar da ideia de que há qualquer dom ou mérito pessoal prescrito à trajetória universitária; tornando-se, então, imprescindível analisar as desigualdades nas trajetórias acadêmicas a partir da denúncia da falácia do discurso meritocrático (NOGUEIRA; NOGUEIRA, 2002). Sendo assim, esses sujeitos estão implicados em um movimento de politizar as bases de sustentação das condições de produção do conhecimento científico e os meios de alcançá-lo. A pluralização racial e econômica da universidade, nessa atmosfera, tem colocado em questão as práticas pedagógicas, os valores, os temas de investigação e, sobretudo, questionando-nos: quem pode ser o sujeito da enunciação científica?

Somente com outras histórias do povo negro (políticas, simbólicas, culturais e intelectuais) que outros saberes podem se tornar relevantes para uma instituição de saber como a universidade. Assim, as políticas públicas voltadas para a equidade racial - como as cotas, bem como o reconhecimento da história, da ação do movimento negro e da intelectualidade antirracista - são essenciais para que os brancos e a elite intelectual consigam se deslocar da posição de norma e hegemonia epistêmica; deslocando os pactos da branquitude e desmistificando o branqueamento enquanto um projeto único de saber, universidade e sociedade (SCHUCMAN, 2012; BERNARDINO-COSTA; GROSFOGUEL, 2016).

\section{Considerações Finais}

É possível identificarmos uma pluralidade muito grande nessas experiências universitárias negras; mostrando-nos que a trajetória racial universitária no Brasil é, radicalmente, heterogênea (TEIXEIRA, 2003). Para além da perspectiva da desumanização imposta pela sociedade branca hegemônica, por meio das desigualdades de poder; existem outras práticas sociais, outros processos educativos e outras formas de desenvolver a subjetividade racial que estão em curso no Brasil (GOMES, 2017; NOGUEIRA, 2014). Toda essa ampliação complexifica o nosso olhar para o problema da classe média negra universitária, uma vez que é notável o fato de que construções polarizadas entre 
pureza/resistência e manipulação cultural/ajustamento da cultura afro-brasileira mais atrapalham do que ajudam na investigação da ascensão dos negros em direção ao mercado de consumo material e intelectual (SANSONE, 2000).

A participação de negros nos espaços da classe média - e, portanto, na universidade não apenas altera as dimensões socioeconômicas do país, mas, sobretudo, possui um potencial para a construção de outros valores sociais que contribuam para reconfigurações da visão de mundo e da perspectiva de vida dos sujeitos e da sociedade. Esses sujeitos querem poder compor, por exemplo, espaços de construção intelectual e reforçam a importância de docentes/pesquisadores negros na universidade. Nessa direção, precisamos pactuar com a produção de um conhecimento que crie possibilidades de mediações para que haja a construção de identidades raciais brancas, não mais como dominação, supremacia e normatividade; mas sim como diferenças que coexistam com outras experiências de formas não hierárquicas (GUIMARÃES, 2016).

A potência revolucionária epistêmica, nesse caso, recai sobre uma revisão epistemológica que possa romper e interpelar pensamentos, lógicas, conhecimentos, discursos, práticas e posições que foram construídas a partir de lugares de poder euro e brancocentrados. Nessa direção, é primordial que a experiência dos sujeitos negros e populares - longe de ser a resposta única para a construção de um horizonte democrático possa ser incluída nas narrativas que participam da construção do conhecimento e das dinâmicas institucionais; inclusive em áreas e campos do conhecimento fora dos já, historicamente, possíveis aos negros; como as licenciaturas e os cursos noturnos, por exemplo (BELTRÃO; TEIXEIRA, 2004). Dessa forma, a proposta dos universitários negros de classe média, aqui levantada, não é abandonar a pesquisa ocidental ou (quase) tudo o que se produziu nos últimos séculos; mas, sobretudo, rever aqueles conceitos, motivos e ideias do cânone que são sustentáculo aos modelos de conhecimento que tentam disfarçar suas ideias discriminatórias por meio de discursos de objetividade e neutralidade científicas (BOURDIEU, 2003; OLIVEIRA, 2014; BERNARDINO-COSTA; GROSFOGUEL, 2016).

A politização racial e coletiva desses universitários, dentro e fora da universidade, têm produzido discursos que leem essas experiências a partir de uma afirmatividade negra; consolidando um debate e uma nova semântica para a interpretação e a interpelação dos fenômenos humanos, coletivos, políticos, institucionais e universitários. Com isso queremos dizer que a participação em movimentos antirracistas tem ampliado e reconfigurado a visão e o combate ao racismo no Brasil; corroborando com esse processo de identificação do racismo 
como um problema da estrutura brasileira e não como um infortúnio da desigualdade econômica (SCHWARTZMAN, 2009). Ademais, tencionando com a própria literatura em torno dos negros da classe média brasileira, essa nova geração de jovens negros parece vacilar a prescrição de que o caminho para a ascenção econômica e acadêmica precisa ser individual e assimilado aos códigos brancocentrados.

\begin{abstract}
Dandara: O meu estudo foi priorizado, eu sou filha única, os meus pais não tinham que gastar com outra criança, então, é muito complicado, meio que te excluem de certas decisões, porque você, sei lá, você não teve que trabalhar com 17 anos, mas eu não sou menos preta por isso (...) Não, não mesmo, dinheiro não embranquece ninguém, talvez tem gente que até acha, mas isso não me embranqueceu em nenhum momento. Isso talvez me possibilitou de ter ferramentas pra reagir a isso de outra maneira, além do óbvio né, que é ter mais tempo pra estudar, essas coisas, mas isso me possibilitou a ter outras ferramentas de reação e de acesso, mas isso não me embranqueceu, inclusive me empreteceu (...)
\end{abstract}

Ou seja, ainda com a ascensão social, o aburguesamento, o sucesso pessoal e a entrada na universidade pública, nada evitou - nunca - que um negro fosse um negro no Brasil (FIGUEIREDO, 2002; GUIMARÃES, 2016). Deve-se, nesse sentido, potencializar o uso das brechas e dos furos institucionais que técnicos administrativos, estudantes e professores da universidade - não conformistas - se apropriam para fomentarem o debate antirracista na universidade por meio de palestras, debates, aulas abertas, mesas redondas, oficinas e a oferta de disciplinas acerca do debate sobre a desigualdade de raça; politizando as estruturas racistas e as desvinculando, subalternamente, às desigualdades econômicas (hooks, 2013). Por fim, os sujeitos de pesquisa apontam para a importância das ações afirmativas como sendo, para além de uma política de reserva de vagas para pobres, um projeto societário que garanta que sujeitos, compulsória e historicamente, expulsos da universidade; possam ter os seus saberes, práticas e vivências considerados um campo de saber/viver legítimo. Um campo que redimensione as verdades e as violências (brancocentradas e elitistas) que, historicamente a universidade sedimentou como sendo a sua única face. Sendo assim, enquanto a universidade continuar sendo um local sagrado de suposto saber e de propagações técnico-ideológicas que produz des(naturalizações) que des(humanizam) os descendentes afro-brasileiros; ela será o alvo da interpelação de práticas, críticas e perspectivas, epistemo e politicamente, enegrecidas

\title{
Referências Bibliográficas
}

AGUIAR, Márcio Mucedula. "A construção das hierarquias sociais: classe, raça, gênero e etnicidade". Cadernos de Pesquisa do CDHIS, v. 1, n. 37, 2007.

ANDREWS, George Reid. "Democracia racial brasileira 1900-1990: um contraponto americano". Estud. av., São Paulo, v. 11, n. 30, p. 95-115, 1997 
ANDREWS, George Reid. América afro-latina, 1800-2000. EdUFSCar, 2007.

AZEVEDO, Celia Maria Marinho de. Anti-racismo e seus paradoxos: reflexões sobre cota racial, raça e racismo. Annablume, 2004.

BELTRÃO, Kaizô Iwakami; TEIXEIRA, Moema De Poli. "O vermelho e o negro: raça e gênero na Universidade brasileira: uma análise da seletividade das carreiras a partir dos censos demográficos de 1960 a 2000”, IPEA, 2004

BERNARDINO-COSTA, Joaze; GROSFOGUEL, Ramón. "Decolonialidade e perspectiva negra". Sociedade e Estado, v. 31, n. 1, p. 15-24, 2016.

BOURDIEU, Pierre. Usos sociais da ciência. Unesp, 2003.

CARNEIRO, Sueli. "Racismo, sexismo e desigualdade no Brasil: consciência em debate". Selo Negro, 2011.

CARTER, Prudence L. Keepin'it real: School success beyond Black and White. Oxford University Press, 2005.

CARVALHO, Isabel Cristina Moura. "Biografia, identidade e narrativa: elementos para uma análise hermenêutica". Horizontes antropológicos, v. 9, n. 19, p. 283-302, 2003.

CARVALHO, José Jorge de. “'Espetacularização' e 'canibalização' das culturas populares na América Latina”. Revista Anthropológicas, v. 21, n. 1, 2012.

CASTRO, Ricardo Dias. Nós queremos reitores negros, saca?: trajetórias de universitários negros de classe média na UFMG. Dissertação (Mestrado em Psicologia). Faculdade de Filosofia e Ciências Humanas, Universidade Federal de Minas Gerais, Belo Horizonte, 2017.

CASTRO, Ricardo Dias; MAYORGA, Claudia. "A construção de um campo de pesquisa antirracista ou sobre quando sujeito e objeto (se) pesquisam". Revista da Associação Brasileira de Pesquisadores/as Negros/as (ABPN), v. 10, n. 24, p. 339-365, 2018.

CHAUÍ, Marilena. "O que é ideologia”. In Coleção primeiros passos (Vol. 13). Brasiliense, 2004

CHAUÍ, Marilena. "A universidade pública sob nova perspectiva”. Revista brasileira de educação, v. 24, p. 5-15, 2003.

CLANDININ, D. Jean; CONNELLY, F. Michael. Pesquisa narrativa: experiência e história em pesquisa qualitativa. Uberlândia, Brasil, 2011.

CUNHA, Luiz Antônio. "Ensino superior e universidade no Brasil”. Lopes, EMT et al, v. 500, p. 151-204, 2000.

D'ADESKY, Jacques. Pluralismo étnico e multiculturalismo: racismos e antirracismos no Brasil. Rio de Janeiro: Pallas, 2003. p. 194

DÁVILA, Jerry. Diploma de brancura: política social e racial no Brasil, 1917-1945. Unesp, 2006.

FERES JUNIOR, João; DAFLON, Verônica Toste. "Ação afirmativa na Índia e no Brasil: um estudo sobre a retórica acadêmica". Sociologias, v. 17, n. 40, 2015. 
FERES JUNIOR, João. "Aspectos semânticos da discriminação racial no Brasil para além da teoria da modernidade". Revista Brasileira de Ciências Sociais, v. 21, n. 61, p. 163-226, 2006.

FIGUEIREDO, Ângela. "Fora do jogo”. Cadernos Pagu, v. 23, p. 199-228, 2004.

FIGUEIREDO, Ângela. Classe média negra: trajetórias e perfis. EDUFBA, 2012.

FIGUEIREDO, Ângela. Novas elites de cor: estudo sobre os profissionais liberais negros de Salvador. Annablume, 2002.

FIGUEIREDO, Ângela; FURTADO, Cláudio Alves. “As elites negras”. In: SANSONE, Lívio; FURTADO, Cláudio Alves. (Org.). Dicionário crítico das ciências sociais dos países de fala oficial portuguesa, Salvador, EDUFBA, 2014, p. 131-149

FONSECA, Marcus Vinícius. BARROS, Aaronovich Pombo. (Orgs.). A história da educação dos negros no Brasil. Niterói: EdUFF, 2016.

FONTE, Carla. A narrativa no contexto da ciência psicológica sob o aspecto do processo de construção de significados. Psicologia: teoria e prática, v. 8, n. 2, p. 123-131, 2006.

GOMES, N.L. Movimento Negro Educador: saberes construídos nas lutas por emancipação. Petrópolis: Vozes, 2017

GROSFOGUEL, Ramón. "A estrutura do conhecimento nas universidades ocidentalizadas: racismo/sexismo epistêmico e os quatro genocídios/epistemicídios do longo século XVI”. Sociedade e Estado, v. 31, n. 1, p. 25-49, 2016.

GUIMARÃES, Antônio Sérgio Alfredo. "Formações nacionais de classe e raça". Tempo Social, v. 28, n. 2, p. 161-182, 2016.

GUIMARÃES, Antônio Sergio Alfredo. "Raça e os estudos de relações raciais no Brasil". Novos Estudos CEBRAP, v. 54, p. 147-156, 1999.

hooks, bell. "Confrontação da classe social em sala de aula". In: Ensinando a transgredir: a educação como prática da liberdade. São Paulo, 2013.

LERNER, Samara Mancebo. “A política de cotas raciais no Brasil segundo a percepção de negros de camadas médias do Rio de Janeiro". Sociedade e Cultura, v. 17, n. 2, 2015.

LIRA, David Pessoa. de; TRINDADE, Celio Juliano Barroso. "Elementos epistemológicos e filosóficos etnocêntricos: inversão de paradigmas afro em diáspora". Estudos Teológicos, v. 55, n. 1, p. 34-46, 2016.

MAGGIE, Yvonne; FRY, Peter. "A reserva de vagas para negros nas universidades brasileiras”. Estudos avançados, v. 18, n. 50, p. 67-80, 2004.

MAYORGA, Claudia. Universidade cindida, universidade em conexão. UFMG, 2010.

MAYORGA, Claudia; SOUZA, Luciana Maria de. "Ação Afirmativa na Universidade: a permanência em foco". Revista Psicologia Política, v. 12, n. 24, p. 263-281, 2012.

MUNANGA, Kabengele. "Políticas de ação afirmativa em benefício da população negra no Brasil: um ponto de vista em defesa de cotas". Sociedade e cultura, v. 4, n. 2, p. 31-43, 2001.

NASCIMENTO, Abdias. O genocídio do negro brasileiro: processo de um racismo 
mascarado. Editora Perspectiva SA, 2016.

NOGUEIRA, Cláudio Marques Martins; NOGUEIRA, Maria Alice. "A sociologia da educação de Pierre Bourdieu: limites e contribuições”. Educação \& Sociedade, v. 23, n. 78, p. 15-36, 2002.

NOGUEIRA, Oracy. "Preconceito racial de marca e preconceito racial de origem: sugestão de um quadro de referência para a interpretação do material sobre relações raciais no Brasil”. Tempo social, v. 19, n. 1, p. 287-308, 2007.

NOGUEIRA, Simone Gibran. Processos educativos da Capoeira Angola e construção do pertencimento étnico-racial. São Carlos: UFSCar, 2007.

OLIVEIRA SARAIVA, Luís Fernando de et al. "A 'nova classe média': repercussões psicossociais em famílias brasileiras”. Psicologia USP, v. 26, n. 1, p. 52-61, 2015.

OLIVEIRA, Luiz Fernandes de. "Educação Antirracista: tensões e desafios para o ensino de sociologia”. Educação \& Realidade, v. 39, n. 1, 2014.

OLIVEN, Arabela Campos. "Ações afirmativas, relações raciais e política de cotas nas universidades: Uma comparação entre os Estados Unidos e o Brasil”. Educação, v. 30, n. 61, p. 29-51, 2007.

OSORIO, Rafael Guerreiro. A mobilidade social dos negros brasileiros, IPEA, 2004.

PINHEIRO, Luana et al. Retrato das desigualdades de gênero e raça. IPEA, 2008.

PIRES, Mara Fernanda Chiari. "Docentes negros na universidade pública brasileira: docência e pesquisa como resistência e luta". 234p. Tese de Doutorado, Faculdade de Educação da Universidade Estadual de Campinas, UNICAMP, Campinas. 2014.

QUIJANO, Aníbal. “Colonialidade do poder, eurocentrismo e América Latina”. In: Edgardo Lander (Org.). A colonialidade do saber: eurocentrismo e ciências sociais - perspectivas latino-americanas. Buenos Aires, CLACSO, 2005. p. 227-278

RIBEIRO, Djamila. O que é lugar de fala?. Belo Horizonte: Letramento, 2017.

RODRIGUES, Alan et al. Práticas pedagógicas e a lógica meritória na universidade: trajetórias de estudantes da rede pública. Rio de Janeiro: UFRJ, 2006.

SALATA, André Ricardo. "Quem é classe média no Brasil? Um estudo sobre identidades de classe". Dados-Revista de Ciências Sociais, v. 58, n. 1, 2015.

SANSONE, Lívio. "Os objetos da identidade negra: consumo, mercantilização, globalização e a criação de culturas negras no Brasil”. Mana, v. 6, n. 1, p. 87-119, 2000.

SANTANA, Ivo de. "Negros em colarinhos brancos: estilos de vida, identidades e ascensão social no serviço público”. Cadernos de Estudos Sociais, v. 1, n. 29, 2014.

SANTOS, Boaventura Sousa de. "Para uma sociologia das ausências e uma sociologia das emergências". Revista crítica de ciências sociais, v. 63, p. 237-280, 2002.

SCHUCMAN, Lia Vainer. Entre o encardido, o branco e o branquíssimo: raça, hierarquia e poder na construção da branquitude paulistana. 2012. Tese de Doutorado. Universidade de São Paulo. 
SCHWARTZMAN, Luisa Farah. "Seeing like citizens: unofficial understandings of official racial categories in a Brazilian university". Journal of Latin American Studies, v. 41, n. 2, p. 221-250, 2009.

SCHWARTZMAN, Luisa Farah; SILVA, Graziella Moraes Dias da. "Unexpected narratives from multicultural policies: Translations of affirmative action in Brazil". Latin American and Caribbean Ethnic Studies, v. 7, n. 1, p. 31-48, 2012

SITO, Luanda. "Disputas e diálogos em torno do conceito de 'ações afirmativas' para o ensino superior no Brasil”. universitas humanística, n. 77, 2014.

SKIDMORE, Thomas E. Preto no branco: raça e nacionalidade no pensamento brasileiro. Paz e Terra, 2013

SOARES, Reinaldo da Silva. Negros de classe média em São Paulo: estilo de vida e identidade negra. Tese de Doutorado. Universidade de São Paulo, 2004

SOUZA, Jessé. "Raça ou classe? Sobre a desigualdade brasileira". Lua Nova, v. 65, p. 43 69, 2005.

SOUZA, José. “A gramática social da desigualdade brasileira”. RBCS, v.19, n. 54, 2000.

TAFURI, Diogo Marques. "As Ações Afirmativas e o Campo Científico: dilemas políticos e epistemológicos para a constituição de uma ciência social crítica". Políticas Educativas, v. 5, n. $1 ., 2011$

TEIXEIRA, Moema de Poli. Negros na universidade: identidade e trajetórias de ascensão social no Rio de Janeiro. Pallas Editora, 2003.

emergências". Revista crítica de ciências sociais, v. 63, p. 237-280, 2002.

SOUZA, Jessé. "Raça ou classe? Sobre a desigualdade brasileira". Lua Nova, v. 65, p. 4369, 2005.

SOUZA, José. “A gramática social da desigualdade brasileira”. RBCS, v.19, n. 54, 2000.

TAFURI, Diogo Marques. “As Ações Afirmativas e o Campo Científico: dilemas políticos e epistemológicos para a constituição de uma ciência social crítica”. Políticas Educativas, v. 5, n. $1 ., 2011$

TEIXEIRA, Moema de Poli. Negros na universidade: identidade e trajetórias de ascensão social no Rio de Janeiro. Pallas Editora, 2003.

\section{Classe Média Negra Universitária: por um projeto de sociedade afirmativa}

\footnotetext{
Resumo

Este artigo propõe pensar como sujeitos negros, economicamente privilegiados; posicionam-se em relação às ações afirmativas e a democratização do ensino superior público. Para alcançarmos os nossos pontos de análise, realizamos a construção de quatro narrativas com sujeitos autodeclarados negros e da classe média que estivessem envolvidos em alguma política e/ou grupo antirracista. $\mathrm{O}$ que podemos perceber é que a experiência de ser negro e pertencer a contextos econômicos médios redimensiona a leitura sobre as políticas de cotas para além da reserva de vagas para sujeitos populares nas instituições de ensino superior. Nessa direção, os sujeitos de pesquisa situam a ação afirmativa como sendo uma política econômica; mas, sobretudo, uma produção acadêmico-política que se desloque do elitismo brancocentrado da universidade. A política afirmativa, assim, é lida enquanto um projeto antirracista para a universidade e a sociedade como um todo
} 
Palavras-chave: ação afirmativa, negros, classe média, universidade.

\title{
University black middle class: for an affirmative society project
}

\begin{abstract}
This paper proposes to think how black, economically privileged subjects; position themselves in relation to affirmative actions and the democratization of public higher education. In order to reach our points of analysis, we constructed four narratives with self-declared black and middle class subjects who were involved in some anti-racist policy and / or group. What we can perceive is that the experience of being black and belonging to medium economic contexts resizes the reading about quota policies beyond reserving vacancies for popular subjects in higher education institutions. In this direction, the subjects researched situate affirmative action as an economic policy; but above all, an academic-political production that moves from the white-centered elitism of the university. The affirmative policy, thus, is read as an anti-racist project for the university and society as a whole.
\end{abstract}

Keywords: affirmative action, black, middle class, university

\section{Clase media negra universitaria: por un proyecto de sociedad afirmativa}

\section{Resumen}

Este artículo propone pensar cómo sujetos negros, económicamente privilegiados se posicionan con relación a las acciones afirmativas y a la democratización de la educación superior pública. Para alcanzar nuestros puntos de análisis realizamos la construcción de cuatro narrativas con sujetos auto-declarados negros y de clase media que estuvieran involucrados en alguna política y/o grupo antirracista. Lo que podemos percibir es que la experiencia de ser negro y pertenecer a contextos económicos medios redimensiona la lectura sobre las políticas de cuotas más allá de la reserva de vagas para sujetos populares en las instituciones de educación superior. En esa dirección, los sujetos de investigación sitúan la acción afirmativa como siendo una política económica; pero, sobre todo, una producción académico-política que se desplaza del elitismo blanco-centrado de la universidad. La política afirmativa, así, es leída como un proyecto antirracista para la universidad y la sociedad como un todo.

Palabras clave: acción afirmativa, negros, clase media, universidad. 